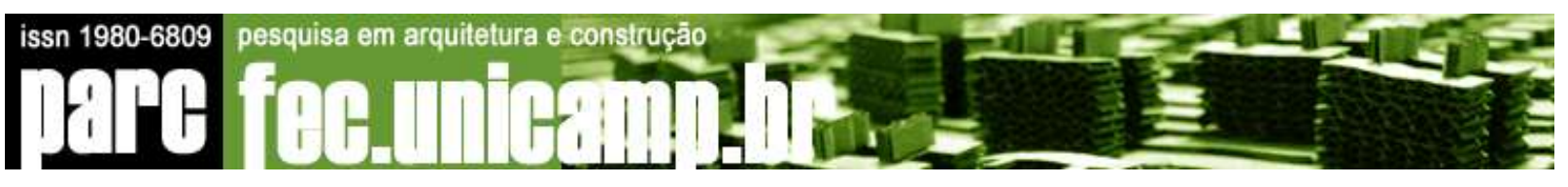

\title{
O processo de projeto na reabilitação: a casa burguesa do Porto
}

The process of the rehabilitation design: the bourgeois house of Oporto

\section{EUGÉNIO COIMBRA ${ }^{1}$}

\section{LUÍS ROMÃO}

1. Arquiteto, Mestre em Arquitetura pela Escola Superior Artística do Porto, Doutorando em Arquitetura na Escola de Arquitetura da Universidade do Minho.

2. Arquiteto, Doutor em Arquitetura pelo Programa de Pós-Graduação em Design and Computation do MIT, professor do Departamento de Desenho e Comunicação Visual da Faculdade de Arquitetura da Universidade Técnica de Lisboa.

Id3089@alunos.uminho.pt

Iromao@fa.utl.pt

\section{Resumo}

Este artigo foi realizado no contexto de uma investigação mais alargada que se pretende desenvolver no presente doutoramento em arquitetura.

É importante preservar o centro antigo das grandes aglomerações urbanas, rico em conhecimento e portador de uma forte carga simbólica. Nesta perspetiva é fundamental pensar a sua integração em estruturas urbanas cada vez mais multipolares que organizam o território (Ascher, 2010).

A casa burguesa do Porto, construída desde o final do século $X V I$ até ao início do século $X X$, é dominante no tecido antigo da cidade e carece de reabilitação.

A partir da análise de uma amostra representativa de um momento da sua evolução, será possível verificar padrões e definir regras. A teoria das gramáticas da forma (Stiny \& Gips, 1972) oferece o formalismo necessário à sistematização destas regras.

O objetivo da investigação em desenvolvimento será apoiar o processo de projeto na reabilitação da casa burguesa do Porto. Sustentando que a análise da sua situação atual, reflexo de intervenções anónimas e de autor, pode sugerir a geração de novas soluções.

Palavras-chave: processo; projeto; reabilitação, gramáticas. 


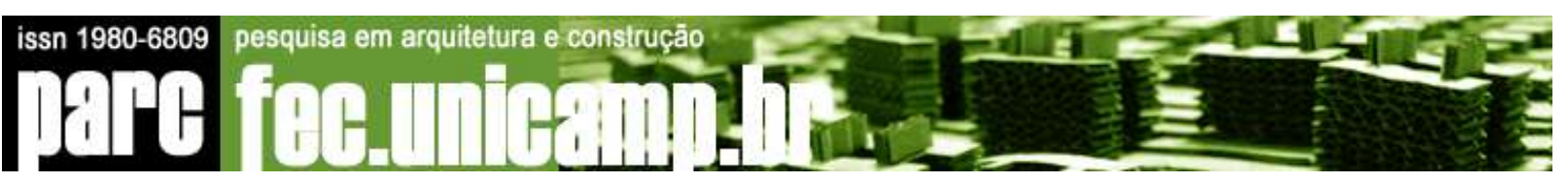

\section{Abstract}

This paper was accomplished in the context of a broader research to be developed in an ongoing $\mathrm{PhD}$ program in architecture.

It is important to preserve the old center of large urban areas, rich in knowledge and full of a strong symbolic charge. This perspective is crucial to think of their integration into urban increasingly multipolar structures organizing the territory (Ascher, 2010).

The bourgeois house of Oporto, built from the late sixteenth century until the early twentieth century, is dominant in the ancient fabric of the city and need rehabilitation.

From the analysis of a representative sample of a moment of its evolution, it will be possible to verify patterns and to define rules. The shape grammars theory (Stiny \& Gips, 1972) provides the required formalism for the systematization of these rules.

The aim of the research is to support a rehabilitation design process of the bourgeois house of Oporto, arguing that the analysis of its current situation, which reflects anonymous and author interventions, may suggest the generation of new solutions.

Keywords: process; design; rehabilitation, shape grammars. 


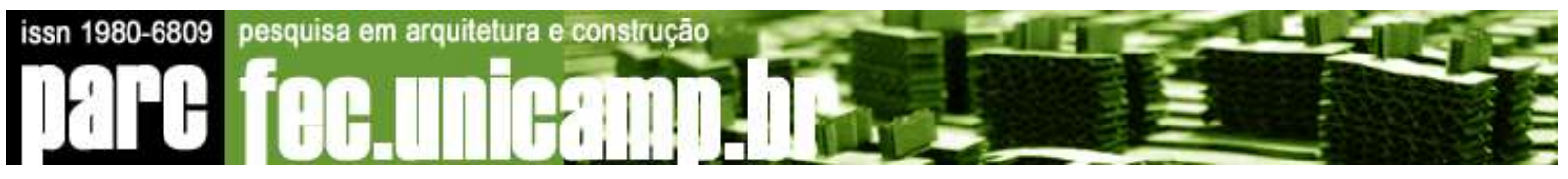

\section{O processo de projeto na reabilitação: a casa burguesa do Porto}

\section{Introdução}

O conjunto edificado das sociedades da segunda metade do século XX pode ser definido por um "urbanismo de redes". Estas redes permitem a libertação de constrangimentos espaciais que determinavam a localização, a implantação e a forma dos estabelecimentos humanos. A promoção de um espaço isotrópico permite uma urbanização difusa e tentacular (Choay, 2008: 256).

A integração do centro antigo, como parte desta configuração mais alargada é potenciada pela preservação do conhecimento e valor simbólico patente no seu património histórico.

A casa é uma peça elementar na conformação das ruas e do tecido da cidade como um todo. No Porto a casa estreita e alta originária do antigo burgo, preponderante no velho coração da cidade e nas ruas que dele irradiaram, perdurou na tradição local, assimilando os sucessivos estilos e técnicas (Oliveira \& Galhano,1992: 322).

A casa burguesa do Porto pela sua dominância e simbolismo apresenta-se como um elemento fundamental na reabilitação do património histórico da cidade. Com o passar do tempo torna-se importante reavaliar a sua organização interna e usos, materiais e sistemas construtivos, num gesto de a recuperar e potenciar as suas características elementares.

A arquitetura é uma obra aberta, não deve ser considerada como um feito mas como um ir fazendo, nunca está terminada prolonga-se no uso (Vieira de Almeida, 2008: 34).

$\mathrm{Na}$ cidade do Porto foi recentemente criada a Porto Vivo, SRU - Sociedade de Reabilitação Urbana da Baixa Portuense S. A. tem como missão conduzir o processo de reabilitação urbana da Baixa Portuense.

Em 2010 foi criado o Plano de Gestão do Centro Histórico do Porto que tem como objetivo incorporar uma visão global e integradora do espaço territorial que o compõe. A reabilitação do centro histórico é prioritária e o documento estratégico aqui referido oferece dados estatísticos importantes, inexistentes para outras áreas da cidade.

O centro histórico é constituído por 1.796 edifícios, 443 em bom estado de conservação, 649 em médio estado, 575 em mau estado e 78 em ruína, estando $51 \mathrm{com}$ obras em curso. A função dominante é a habitação, constituindo $80 \%$ do edificado. A casa burguesa é o tipo de edifício que predomina neste território. 


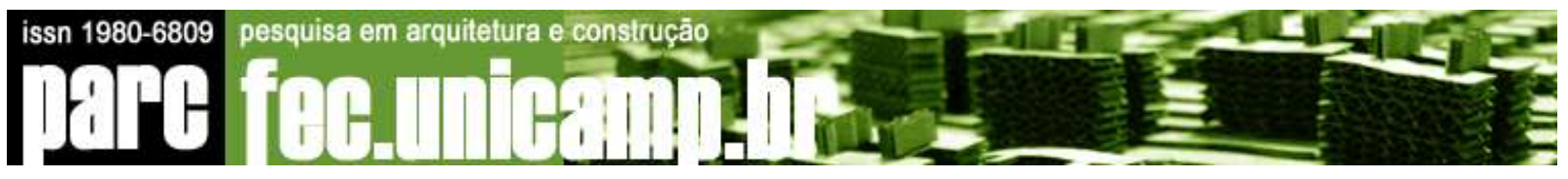

A reabilitação urbana deverá ser prioritariamente realizada pelos proprietários. No entanto, podem acordar com a SRU os termos da reabilitação do seu edifício, encarregando aquela de proceder a essa reabilitação.

Nos fatores críticos de sucesso patentes no relatório de atividades de 2010 da Porto Vivo, podemos identificar como fraquezas a extensão do território e a complexidade das tarefas e como forças, a experiência, o conhecimento e os resultados obtidos.

O propósito da investigação em desenvolvimento é apoiar a reabilitação da casa burguesa do Porto, pelo seu protagonismo no território aqui descrito. Nesse intuito será desenvolvida uma gramática da forma composta (Duarte, 2004).

No lote tradicional da cidade tradicional, os edifícios de uma dada amostra serão estudados do ponto de vista topológico e geométrico assim como construtivo. No reconhecimento de padrões, serão definidas soluções tipo de desenho e soluções tipo construtivas, que na sua descrição possam ser úteis ao processo de projeto, simplificando e tornando mais económica a reabilitação.

\section{A cidade}

François Ascher na sua obra "Novos Princípios do Urbanismo", publicada em 2010, fala de uma realidade social Francesa que, em alguns aspetos, pode ser facilmente transposta para Portugal.

Grande parte da população vive em cidades, as grandes aglomerações urbanas alargam-se e atraem uma parte crescente das atividades, a residência individual estende-se por periferias cada vez mais longínquas, as distâncias percorridas cada dia pelos citadinos aumentam.

Graças ao desenvolvimento das técnicas de transporte e de telecomunicações dá-se um crescimento urbano organizado dentro, à volta e a partir das aglomerações mais importantes. François Ascher (2010: 105) introduz o conceito de metápoles:

“(...) vastos territórios à escala dos quais se organiza a vida urbana, doméstica e económica, formando um espaço urbanizado extenso, descontínuo, heterogéneo, polinuclear, que integra no mesmo conjunto cidade densa e neo-rural, pequena cidade, vila e subúrbio".

Este autor defende que é com esta heterogeneidade que é preciso fazer cidade. As soluções não estão no regresso às formas urbanas antigas nem na continuidade do edificado 


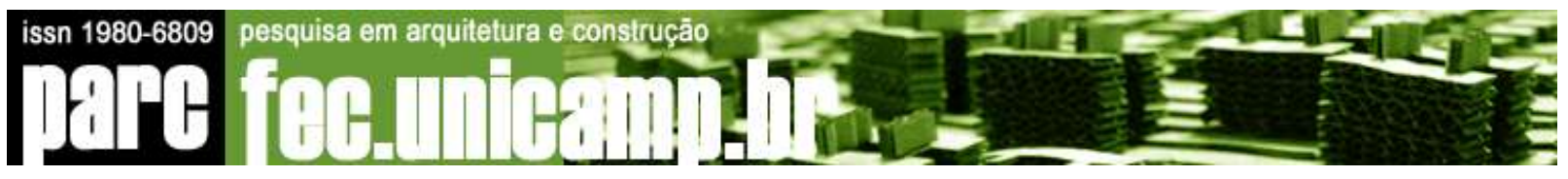

e consequente densidade, embora reconheça nestas características vantagens do ponto de vista ecológico.

As estruturas urbanas são cada vez mais multipolares e o centro antigo das aglomerações assegura um número cada vez mais limitado de funções. Era o lugar mais acessível para todos, o mais bem protegido e o mais rico simbolicamente. Todas as atividades e funções urbanas tentavam localizar-se aí, o que the conferia uma densidade elevada e uma certa mistura funcional (Ascher, 2010: 123).

Em estruturas metapolitanas e multipolares a representação da cidade com um centro e periferia tende a esbater-se, mas nesta polarização o centro esvaziado, deveria voltar a ter algum protagonismo, constituindo-se num polo desta configuração mais alargada.

Giovannoni em meados do século XX, intuía que a cidade compacta e centralizada tendia a apagar-se em benefício de um outro modo de agregação (Choay, 2008: 208).

\section{O património, potencial heurístico}

Património, palavra que podemos facilmente associar a um legado, hoje em dia pode ser requalificada por diversos adjetivos (genético, natural, histórico, ...), tornou-se num conceito nómada profusamente usado (Choay, 2008: 11).

Françoise Choay (2008: 197), lembra Camillo Sitte que em 1889 com a obra "Der Städtebau nach seinen künstlerischen Grundsätzen" (A Urbanização nos seus Princípios Estéticos), a partir do paradigma de praça pública, descreve e explica como desde a antiguidade até à cidade barroca, diferentes configurações espaciais não deixaram de irradiar uma beleza que as praças contemporâneas não conseguem oferecer.

O reconhecimento do papel pedagógico que o património construído pode ter, torna-o num poderoso utensílio heurístico.

Françoise Choay (2008: 200) lembra ainda Viollet-le Duc que, na mesma época, com a obra "Entretiens sur l' Architecture" (Conversas sobre a Arquitetura), assume a mesma atitude em relação à Arquitetura nunca a dissociando do seu contexto mental, social e técnico.

Nas duas obras verifica-se o mesmo princípio binário entre um passado terminado e um futuro em gestação.

O princípio que aqui é enunciado revela-se inspirador, apesar dos resultados práticos que estas obras possam ter tido. 


\section{As gramáticas da forma}

A primeira publicação relativa às gramáticas da forma remonta a 1972 e teve como autores George Stiny e James Gips. No seu estágio inicial começou por ser aplicada na interpretação e avaliação de obras pictóricas. Mais tarde em $1980 \mathrm{com}$ a publicação do artigo "Kindergarten grammars: designing with Froebel's building gifts" (Gramáticas do jardim de infância: projetar com os dons construtivos de Froebel), G. Stiny apresenta uma gramática definida no espaço tridimensional iniciadora das gramáticas arquitetónicas que se seguiram.

As gramáticas da forma podem ser definidas como sistemas algorítmicos para a criação e entendimento de composições diretamente pela computação de formas, no lugar de texto ou símbolos (Knight, 1989).

Estes sistemas são constituídos por um conjunto de regras cuja aplicação leva à criação de uma determinada linguagem de composição. Estas regras são geradoras e ao mesmo tempo descritivas das formas que a compõem.

Em 1976, George Stiny demonstrou como as gramáticas da forma podem ser geradoras e analíticas quando aplicadas na criação de novas linguagens de composição ou no estudo de linguagens já existentes. Segundo Terry Knight (1989) este gesto serviu de base para novas abordagens e foi potenciador da sua utilização na educação e na prática.

\section{A casa burguesa do Porto}

"A casa é sempre o produto de uma grande multiplicidade de elementos inter-relacionados, refletindo condições naturais e históricas, técnicas, estrutura económica e social, gostos, mentalidade e até certos sentimentos, em especial sentimentos de grupo, das pessoas que as constroem e habitam." (Oliveira \& Galhano,1992: 310).

Como Ernesto Oliveira e Fernando Galhano (1992: 310) descrevem, na sua publicação "Arquitetura Tradicional Portuguesa", desde o antigo burgo medieval estendido em belas ruas quinhentistas e ao longo das ruas irradiantes, seis, sete e oitocentistas, povoamento das anteriores estradas de acesso às portas da cidade. Assiste-se a uma aparente falta de uniformidade nas casas que aí se encontram, diferentes feitios, tamanhos e cores marcam a primeira impressão que se possa ter.

Um olhar mais atento, consegue perceber dois tipos fundamentais. Casas na sua maioria com três ou quatro pisos, atingindo por vezes os cinco pisos, com duas ou três janelas ou portas de frente, todas estreitas e altas. Entre elas, mais raras, outras casas largas 


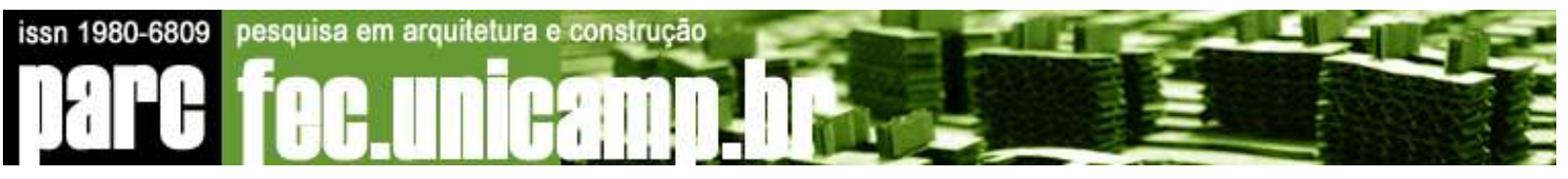

e baixas, compostas essencialmente de rés-do-chão e andar nobre com numerosas portas e janelas de fachada.

Segundo estes autores, a distinção elementar entre estas duas categorias reside em diferentes níveis económicos e sociais. A casa estreita e alta, na sua origem de um tipo híbrido congregando a residência com a atividade comercial. Pertencente à burguesia, detinha as lojas, armazéns e oficinas no rés-do-chão e nos pisos superiores a habitação. A casa larga e baixa é a casa nobre, de espaços amplos como afirmação de prestígio e poder, espelha na cidade o conceito de casa senhorial do campo.

Estes dois tipos não são exclusivos do Porto sendo possível estabelecer relações com outros países europeus. É contudo incontornável que o centro antigo da cidade seja na sua maioria composto por edifícios estreitos e altos, o que lhe confere uma imagem peculiar.

"O Porto é uma cidade grande, feita de casas pequenas - e, aqui e além, alguns raros palácios discretos;" (Oliveira \& Galhano,1992: 319).

Como estes autores afirmam, a casa estreita e alta originária do antigo burgo, preponderante no velho coração da cidade e nas ruas que dele irradiaram, perdurou na tradição local, assimilando os sucessivos estilos e técnicas, acompanhando a evolução da classe de que é própria (Oliveira \& Galhano,1992: 322).

Francisco Barata Fernandes na sua obra "Transformação e Permanência na Habitação Portuense - As formas da casa na forma da cidade" sustenta a seguinte hipótese:

"Existe no Porto uma tipologia de habitação unifamiliar burguesa, cuja matriz de organização interna, de relação com o lote e com o traçado viário se mantém constante (...) desde os finais do século XVI, princípios do século XVII até à primeira metade do século XIX." (Barata Fernandes, 1996: 14).

Este autor toma a cidade como laboratório de Arquitetura. Quanto ao tema da habitação burguesa no Porto considera que se analisarmos o que se passa no lote urbano tradicional, na cidade tradicional, verificamos longas permanências de matrizes tipológicas na cidade.

Francisco Barata Fernandes (1996: 67), nesta sua obra sustenta a existência de três tipos de habitação burguesa dominantes no Porto Os parâmetros de análise usados são os seguintes:

- Relação dominante do lote com o relevo e com o traçado viário;

- Relação entre dimensionamento do lote, edificação e logradouro; 
- Matriz de organização interna do edifício e usos;

- Época e processo de formação do lote; parcelamento da propriedade;

- Materiais de construção e elementos de identidade arquitetónica.

Este autor considera que existe um tipo de edifício de habitação na área da RibeiraBarredo, na baixa de Miragaia e nos Quarteirões compactos da Sé e da Vitória, que é distinto daquele com que se realizará na expansão Almadina, ambos diferem de um terceiro tipo de edifício de habitação que se consolidará a partir da segunda metade do século XIX. Considera três tipos de habitação burguesa, a do Porto Mercantilista, a do Porto lluminista e a do Porto Liberal (Barata Fernandes, 1996: 69).

Francisco Barata Fernandes neste seu estudo é sensível à evolução que estas habitações foram sofrendo e à sua adaptabilidade a novos usos.

O centro histórico do Porto é uma prioridade na estratégia de reabilitação definida para a cidade. O momento a estudar no âmbito do presente doutoramento é o do Porto lluminista que tem início na segunda metade do século XVIII e termina na primeira metade do século XIX.

A razão para esta escolha reside no facto de podermos encontrar exemplos destes edifícios dentro das antigas muralhas (fig. 1) assim como nos eixos de expansão Almadina (fig. 2). Nesta perspetiva para além do centro histórico está a ser considerada a sua envolvente imediata também de intervenção prioritária.

"De meados do século XVIII ao início do século XX, a população do Porto, considerados os limites atuais da cidade, passa de cerca de 35 mil habitantes para quase 200 mil." (Pereira Serén \& Martins in Mota 2010: 54).

A evolução demográfica da cidade tem como consequência o seu crescimento. No final do século XVIII, a cidade expande-se, ultrapassando os limites da sua malha medieval. As operações do regime dos Almadas conquistam novos territórios extramuros (Mota, 2010: 54)

O crescimento da cidade, para além do núcleo medieval, decorre da influência de João de Almada. Tendo chegado ao Porto em 1757, como Governador das Armas do Porto, inicia um plano de refundação da cidade (Nonell in Mota, 2010). Com o propósito de o implementar, cria em 1763 a Junta das Obras Públicas. Em 1786, após a sua morte, é sucedido no cargo pelo seu filho Francisco de Almada e Mendonça. Mais tarde, em 1789 dá-se a demolição do tramo norte da muralha, ultima separação entre a cidade medieval e a sua expansão. (Mota, 2010: 56) 


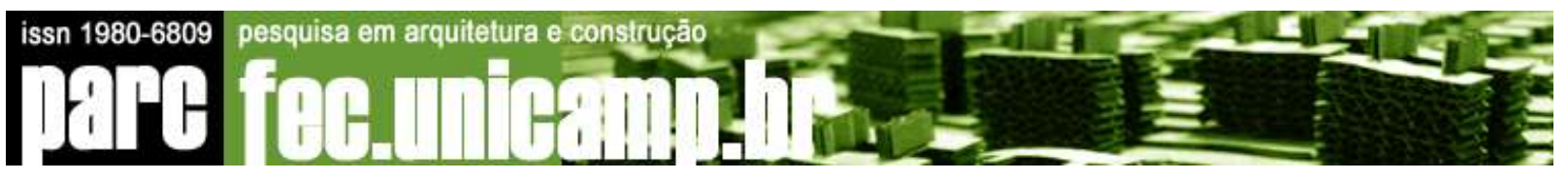

"Com a ação urbanística lançada durante o período pombalino, a cidade ultrapassa o modelo medieval e desenvolve-se em função do novo conceito de estrutura urbana que se pretende criar." (Barata Fernandes, 1996: 142).

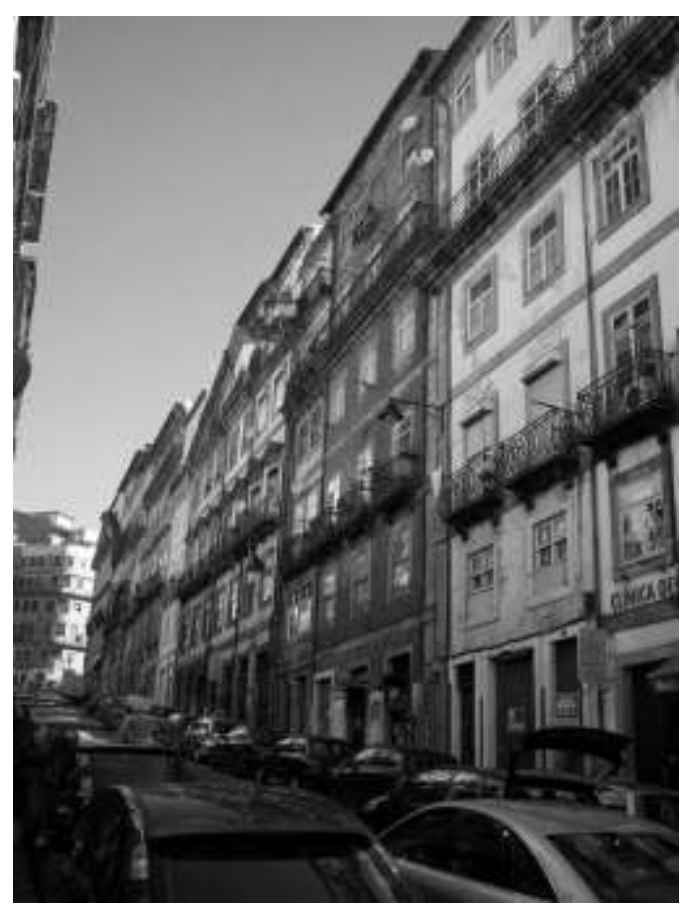

FIGURA 1: Rua de s. João (fotografia do autor).

Como Nelson Mota (2010: 57) refere em 1832 - 34 dá-se a guerra civil, período difícil na história da cidade, e até 1839 não se deram grandes transformações na estrutura urbana da cidade. A Rua dos Bragas surge como alternativa à rua da Boavista na ligação da rua de Cedofeita ao Campo da Regeneração, abrem-se um conjunto de ruas nos terrenos da família Gonçalo Cristóvão, melhorando a relação nascente - poente. Nesta altura a população da cidade encontra-se estagnada, o que se deve em grande parte à conjuntura política.

"Após a vitória liberal (...) vastas extensões de terra, quer no campo quer nas zonas rurais, passaram para as mãos da burguesia, em resultado do processo de expropriação e venda em hasta pública das propriedades pertencentes à nobreza absolutista derrotada e às ordens religiosas." (Teixeira in Mota 2010: 59). 


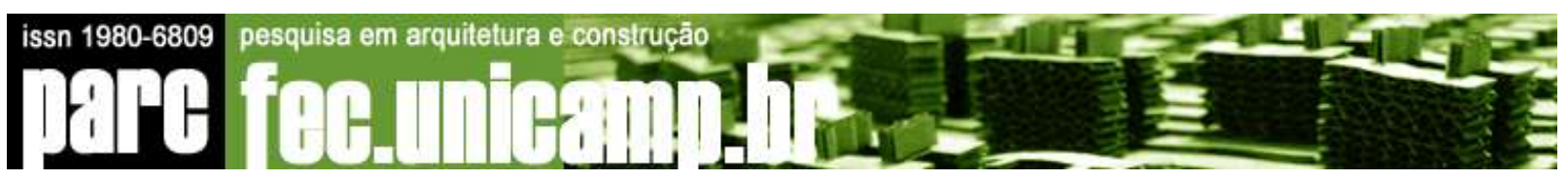

Na passagem do segundo para o terceiro quartel do século XIX, com uma evolução demográfica considerável, revigora-se o crescimento da cidade. O Porto como cidade industrial começa a afirmar-se.

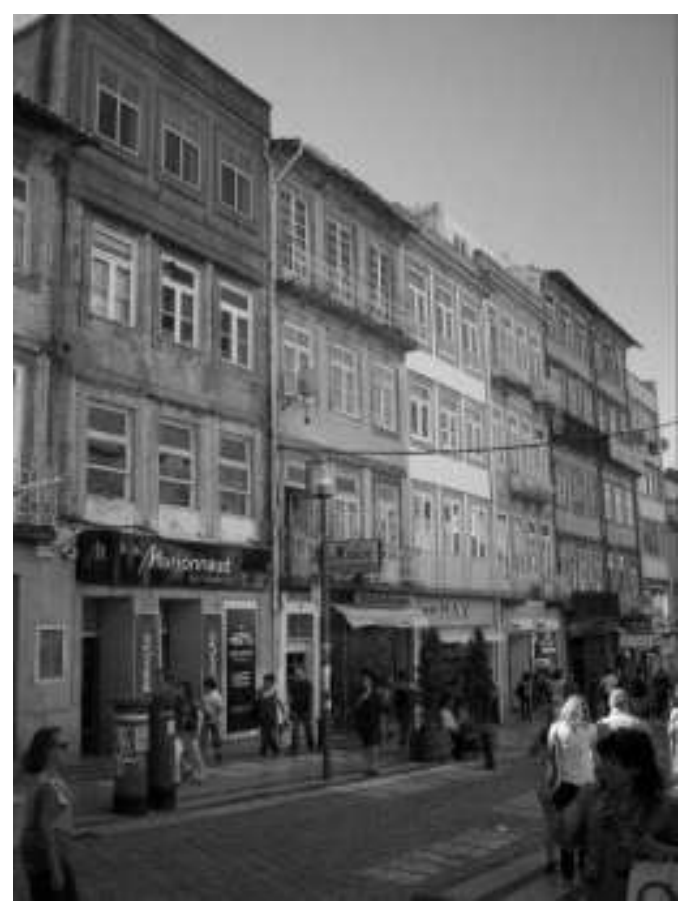

FIGURA 2: Rua de santa Catarina (fotografia do autor).

\section{A caracterização da amostra}

A casa burguesa do Porto pela sua dominância e simbolismo apresenta-se como um elemento fundamental na reabilitação do património histórico da cidade.

Segundo Francisco Barata Fernandes (1996: 143), no período lluminista, momento a ser estudado, a casa burguesa (fig. 3) assumia as seguintes características:

- Frentes sistematicamente maiores, construções mais profundas relativamente ao período anterior, lote sempre com uma área destinada ao logradouro;

- Na relação com a rua verifica-se a preocupação de se controlar um desenho de conjunto, utilização sempre que possível, de um eixo de simetria na regularização de cérceas e na sistematização dos principais elementos arquitetónicos de composição; - A relação entre o dimensionamento do lote, edificação e logradouro varia principalmente no tamanho do logradouro;

- Frentes constantes, variando entre os 5 e 7 metros; 


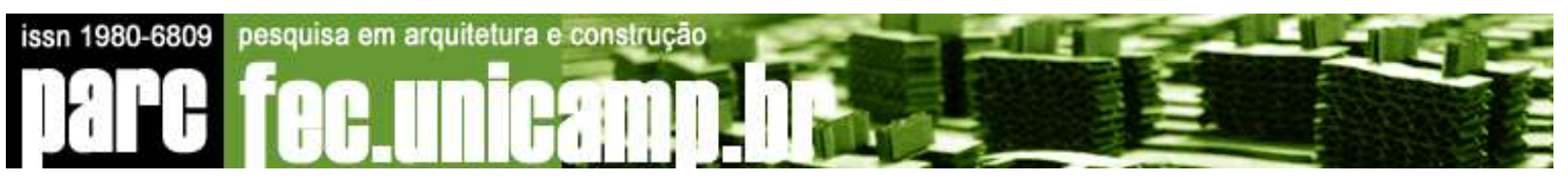

- A profundidade da construção apresenta dois subgrupos com profundidades próximas aos 12 e 22 metros,

- Os logradouros apresentam grandes variações;

- Edifícios com duas frentes e alturas que variam entre os três e os cinco pisos;

- O número de vãos por frente de lote é quase sempre três, verificam-se soluções mais variadas para as padieiras com o uso do arco, surgimento de pequenas janelas quadradas sobre as portas do piso térreo;

- Na matriz da organização interna a caixa de escadas central era estruturante;

- Os materiais são fundamentalmente o granito e a madeira, as fachadas erguem-se em alvenaria de granito, a estrutura dos pavimentos e coberturas é madeira, as paredes divisórias interiores são em tabique, os aumentos de pisos eram fabricados em madeira e taipa, maior uso do ferro nas guardas de varandas e sacadas.

É importante referir que o facto da profundidade dos edifícios ser quase sempre constante e a profundidade dos logradouros ser aleatória, revela que o elemento de planeamento era a rua e não o quarteirão.
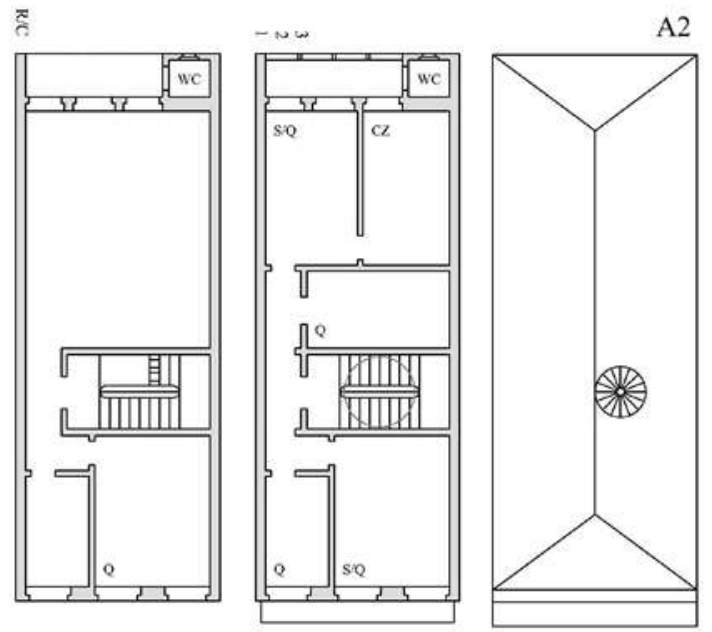

Al
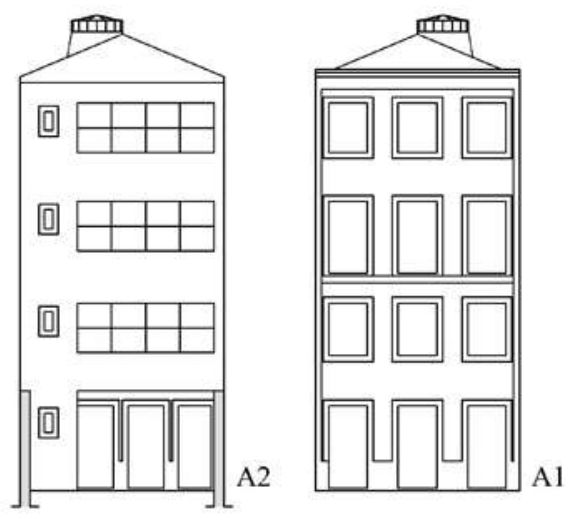

FIGURA 3: Edifício com duas frentes e logradouro, localizado em quarteirão de interior amplo (desenho sem escala). Adaptado de Barata Fernandes (1996: 156).

As construções da segunda metade do século XVIII podem revelar influências de cidades italianas como Génova, Bolonha, Pavia, Florença, assim como, de cidades do Norte da Europa. A sua matriz espacial de organização interna foi sofrendo transformações até se consolidar com autonomia e identidade local (Barata Fernandes, 1996: 68). 


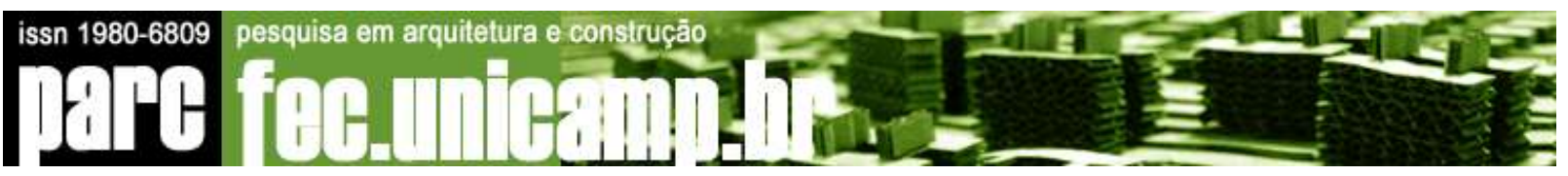

A casa burguesa do Porto, construída desde o final do século XVI até ao início do século XX, surgida do impulso de razões históricas e sociais, soube adaptar-se a novas circunstâncias e técnicas, generalizando-se de modo quase absoluto na cidade (Oliveira \& Galhano,1992: 345).

A amostra composta por edifícios relativos ao momento lluminista, será estudada do ponto de vista topológico e geométrico assim como construtivo. No reconhecimento de padrões, serão definidas soluções tipo de desenho e soluções tipo construtivas, a sua descrição servirá de apoio ao processo de projeto na reabilitação.

\section{A tectónica}

"Na origem grega o termo tectónica deriva da palavra tekton, que significa carpinteiro ou construtor. (...) É evidente que o papel do tekton levaria à eventual emergência do mestre construtor ou architekton." (Frampton, 1998: 23).

A tectónica como a arte das junções, arte entendida como contendo tekne, indicando a tectónica como montagem não só de partes construtivas mas também de objetos mesmo de obras de arte (Borbein in Frampton, 1998: 23).

Semper (in Frampton, 1998: 24) na sua obra "Die vier Elemente der Baukunst" (Os Quatro Elementos da Arquitetura, 1851) apresenta uma outra abordagem à habitação primordial, diferente da conceção neoclássica da cabana primitiva enunciada pelo Abade Laugier no seu "Essai sur L'architecture" (Ensaio sobre a Arquitetura) de 1753.

Segundo Semper a habitação primordial seria composta por quatro elementos fundamentais, as fundações, o lugar do fogo, a estrutura e cobertura e a membrana leve de fecho ou revestimento. Este autor classifica o trabalho da construção em dois procedimentos elementares, a tectónica da estrutura onde componentes leves e lineares são montados originando uma matriz espacial, e a estereotomia das fundações, onde massa e volume são formados em conjunto através do empilhamento repetitivo de elementos pesados.

A diferenciação entre pesado e leve pode ser facilmente associada a sistemas construtivos. Como é o caso de uma parede maciça de pedra ou uma parede em tabique. A primeira serve-se de um material que trabalha sobretudo à compressão e está associada a funções de suporte. A segunda, em madeira, revela a sua qualidade tênsil, com funções sobretudo de compartimentação, tem uma resposta mais flexível às solicitações que a estrutura do edifício possa sofrer. Na parede em tabique a sua própria armação, com a aplicação do fasquiado, pode ser facilmente comparada ao têxtil ou à cestaria (fig. 4). 

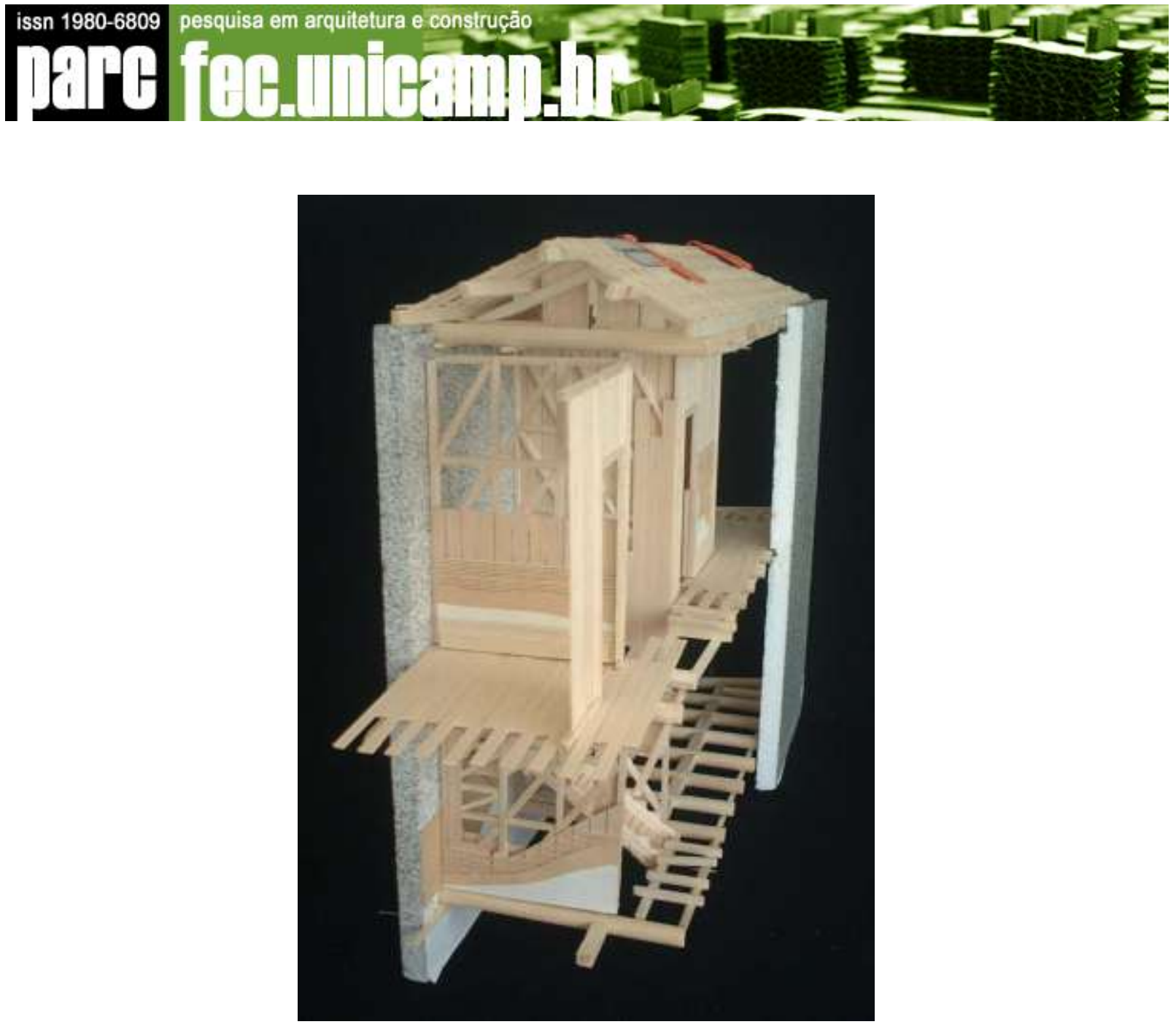

FIGURA 4: Maqueta da estrutura dos sobrados, cobertura, caixa de escadas e paredes interiores de uma casa localizada na rua de Trás. Neste exemplo, as paredes da caixa de escadas, em tabique simples reforçado, são constituídas por uma estrutura de barrotes dispostos em forma de frechais, prumos, travessanhos e escoras, revestida em ambas as faces por um tabuado colocado na vertical. Maqueta realizada por um grupo de alunos do ano letivo 2001/2002 - FAUP (Teixeira, 2004: 90).

Contudo, como Semper (in Frampton, 1998: 25) sugere,

"A história da cultura manifesta transposições ocasionais em que atributos arquitetónicos de um modo são expressos noutro como forma de reter o seu valor simbólico tradicional."

Esta ideia é exemplificada com o caso do templo Grego, onde a pedra é cortada e disposta numa reinterpretação da típica estrutura de madeira (fig. 5).

A estrutura - a imaterialidade e a massa - a substância, dois modos fundamentais da construção, a massa compressiva e a estrutura tênsil. 

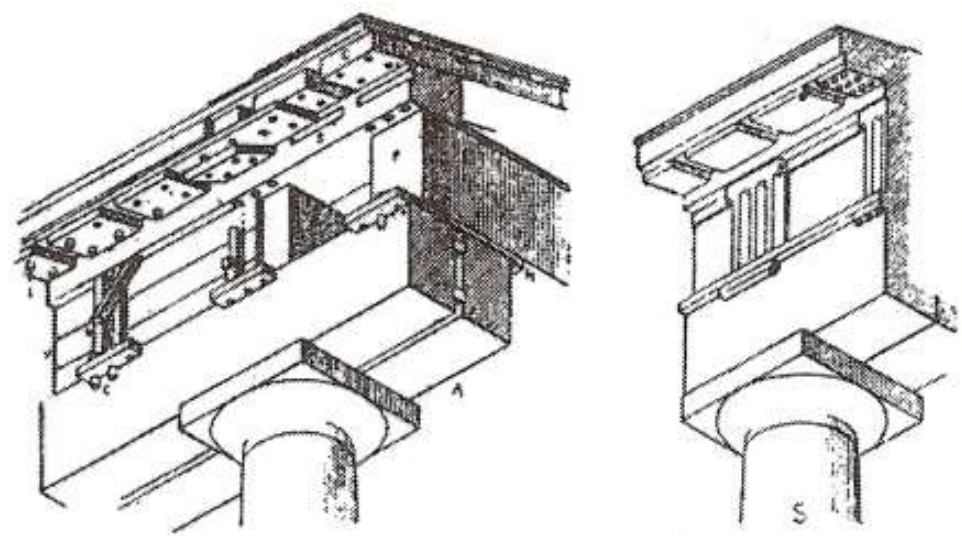

FIGURA 5: A derivação da ordem Dórica a partir da construção em madeira (Choisy in Frampton, 1998: 24).

Segundo M. Frier (et al., 2010) Semper nos seus estudos históricos, teve como preocupação perceber a origem da construção. Relacionou as condições primitivas da arquitetura com o desenvolvimento das competências do homem. Tendo como foco as técnicas da cerâmica e da tecelagem, que para este autor foram as técnicas primordiais, começou a procura de um conhecimento geral sobre a arquitetura. A sua base assenta num estudo comparativo com estas técnicas.

“(...) é certo que o inicio da construção coincide com o inicio dos têxteis. (...) Podemos ver a cerca de varas e ramos entrelaçados como a primeira partição produzida pelo homem, cuja elaboração requer uma técnica que a natureza, por assim dizer, colocou nas mãos do homem." (Semper, 2004: 247).

O interesse de Semper nas técnicas da cerâmica e especialmente da tecelagem, acabou por se manifestar num apelo por uma representação da vida, do lar, da outra vida, como parte integrante da ideia inicial de construção. Os seus estudos levam-no à formulação dos quatro elementos da arquitetura, a terra, o telhado, o encerramento e o empilhamento. Para este autor a tecelagem como forma de construção desempenha um papel fundamental na história da arte. Semper descreve a construção como um espaço sensorial e como uma matéria técnica e prática onde o fechamento ou delimitação é definido dualmente com a suavidade do têxtil e com a rigidez da parede. 


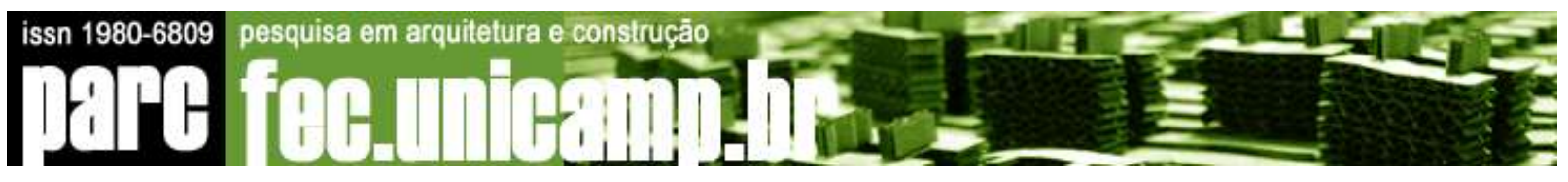

"O uso do trabalho de verga para separar propriedades, o uso de tapetes como revestimento do chão, como proteção contra os elementos e na subdivisão do espaço dentro de uma habitação, em muitos casos precedeu a parede de alvenaria, particularmente quando o clima o favorecia." (Semper, 1989: 103).

Frampton (1998: 23) apresenta um detalhe do pavimento do parque da colina Philopapou construído em Atenas em meados do século $\mathrm{XX}$, da autoria do arquiteto Dimitris Pikionis. Serve para ilustrar como este contínuo topográfico, uma tapeçaria de pedra, transcende as nossas perceções estéticas e funcionais (Fig.6).

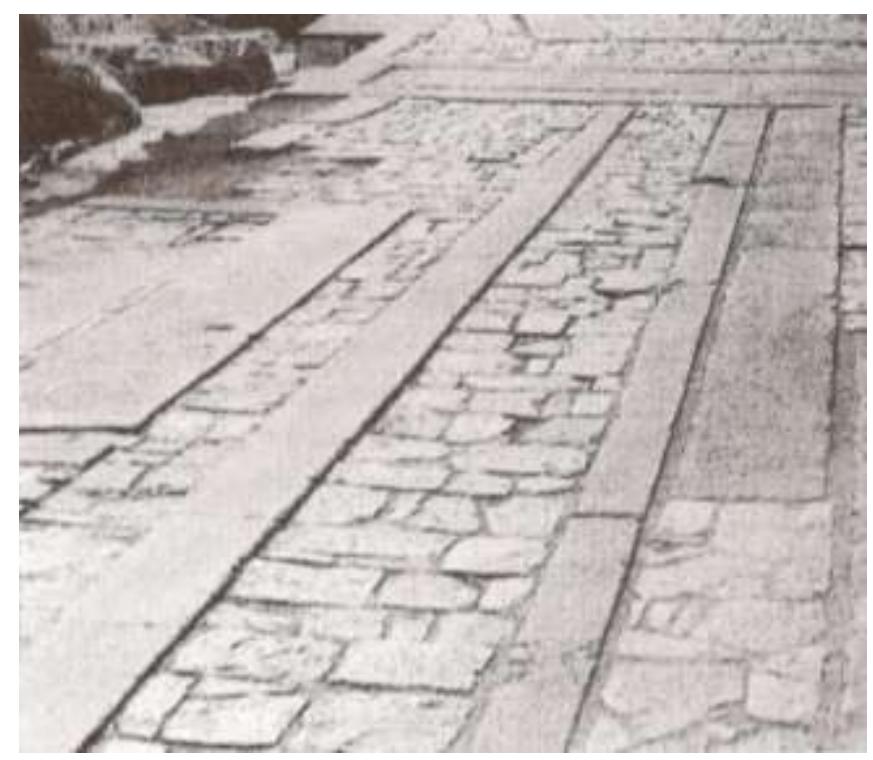

FIGURA 6: Detalhe do pavimento do parque da colina Philopapou de Dimitris Pikionis, Atenas, 1951 1957 (Frampton, 1998: 29).

A superfície do solo é sentida através da locomoção do corpo em ligação com a ressonância acústica do lugar, que confirma o conjunto.

"A maior parte das pessoas diria provavelmente que a arquitetura não produz som. Não podemos ouvi-la. Mas ela não erradia luz e no entanto nós podemos vê-la. Vemos a luz que ela reflete e por isso temos uma impressão da forma e dos materiais. Compartimentos de forma diferente e feitos de materiais diferentes reenviam o som de forma diferente. (...) Recebemos uma impressão global daquilo que observamos e não pensamos nos outros sentidos que contribuíram para essa impressão." (Rasmussen, 2002: 265). 


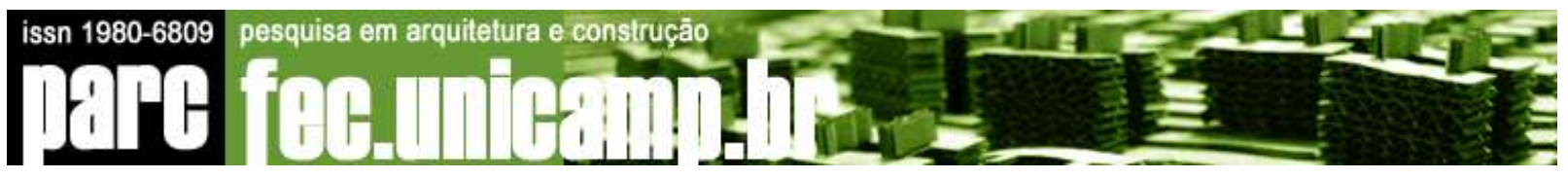

Frampton, relativamente à capacidade do ser experimentar o mundo sensorialmente, lembra Giambattista Vico e o conceito de imaginação corpórea que este propôs na "Scienza Nuova" (Ciência Nova) de 1730. Nesta abordagem sublinha a importância da apropriação táctil da realidade.

As pessoas servem-se do toque para se apropriarem de um objeto. Em alguns edifícios podemos notar como o toque com o passar do tempo foi deixando a sua marca. Não podemos alienar o mundo das ideias da experiência corpórea e dispensar a presença física da arquitetura. Na perceção do lugar temos a oportunidade de nos apercebermos de nós.

"O corpo articula o mundo. Simultaneamente o corpo é articulado pelo mundo. Quando "Eu" apreendo o betão como sendo qualquer coisa fria e dura, "Eu" reconheço o corpo como sendo quente e macio." (Tadao Ando in Frampton, 1998: 31).

As propriedades dos materiais, o seu tratamento, a sua disposição, permitem uma aproximação à arquitetura que só é possível presencialmente quando a percorremos.

\section{A casa burguesa - sistema construtivo}

Joaquim Teixeira (2004) no seu estudo "Descrição do sistema construtivo da casa burguesa do Porto entre os séculos XII e XIX" começa por referir como ao longo do tempo, materiais e sistemas construtivos condicionaram e foram condicionados pela arquitetura.

Segundo este autor, é possível encontrar características semelhantes entre vários sistemas construtivos pertencentes a diferentes estilos arquitetónicos, o que demonstra a existência de princípios universais apesar da variedade de técnicas de extração dos materiais, da sua transformação e aplicação. Como temos o caso do trabalho das alvenarias condicionado às dimensões das peças, ao seu travamento e consolidação, ou o caso da madeira sempre muito condicionada pela dimensão das suas peças, durabilidade e vulnerabilidade ao fogo.

Os chamados materiais tradicionais, como a pedra, a madeira, a cal, a argila, a areia e alguns metais, permanecem inalteráveis durante séculos. Só com a revolução industrial é que se dá uma verdadeira inovação nos sistemas construtivos.

As formas delineadas em projeto, muitas vezes estão à frente das possibilidades técnicas e conhecimentos construtivos existentes e a sua execução obriga a soluções que nem sempre são coerentes. Como é o caso da vontade de uma pureza geométrica que para 


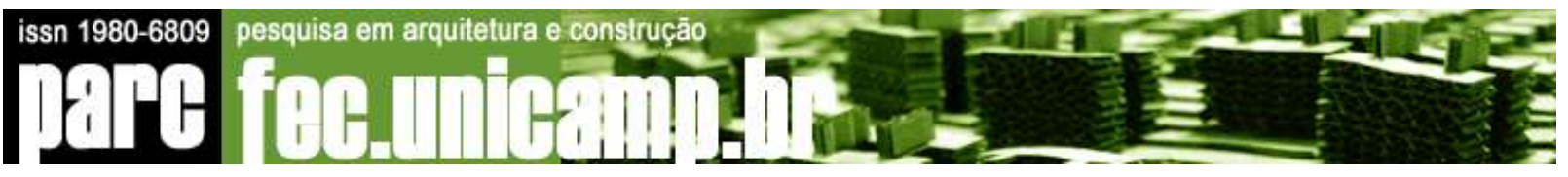

ser exequível requer o uso de complexas soluções construtivas. Apesar da dicotomia projeto construção, é inegável a importância dos sistemas construtivos no fazer arquitetura.

A origem do sistema construtivo da casa burguesa do Porto está seguramente relacionada com os materiais que abundavam dentro e nas imediações da cidade (Teixeira, 2004: 30).

O granito é a pedra que associamos ao Porto, abundante nos arrabaldes da cidade e da qual eram feitos os portais, janelas, cunhais e balcões das casas que a compunham, como é descrito em 1787 por Rebelo da Costa (in Oliveira \& Galhano,1992: 335).

Relativamente à dimensão e forma dos lotes José Ferrão Afonso (in Teixeira, 2004: 31) argumenta que no burgo portuense o anterior parcelamento talvez tenha condicionado e dimensionado a sua divisão. Outro fator importante seria o maior comprimento possível das vigas transversais de madeira que suportavam o sobrado ou a cobertura das antigas habitações agrícolas. $O$ índice de ocupação também terá tido a sua influência.

A casa burguesa do Porto terá sofrido influência de diversas culturas, desde a mourisca na sua perfeição técnica em todos os trabalhos de madeira e pedra até às do norte da Europa de onde se destaca o sistema fachwerk.

O fachwerk é um tipo de tabique feito por setores compreendidos num esqueleto de madeira, com barrotes horizontais e a prumo, cortados por diagonais. Os vãos eram cheios com cacos de barro e tijolos metidos na argamassa (Oliveira \& Galhano,1992: 336).

Ernesto Oliveira e Francisco Galhano (1992) na obra "Arquitetura Tradicional Portuguesa" apontam para uma perspetiva curiosa relativamente aos materiais empregues na construção da casa burguesa do Porto. Associamos esta cidade ao granito, mas grande parte das casas do velho burgo têm as suas frontarias simplesmente em tabique, de ressalto ou lisas, em ambas, as molduras das janelas e portadas, as divisórias dos andares, os entablamentos das varandas e beirais são de madeira.

É de notar que as casas que foram construídas em períodos posteriores, mesmo durante o século XIX, não deixaram de fazer uso da madeira nas paredes de meação, paredes dos pisos acrescentados, paredes de compartimentação interior, pavimentos e na estrutura dos telhados (fig. 7).

Francisco Barata Fernandes (in Teixeira, 2004: 32) relativamente à construção deste tipo de casas afirma que se trata de um saber empírico, adquirido a partir das experiências em obras e dos usos. 


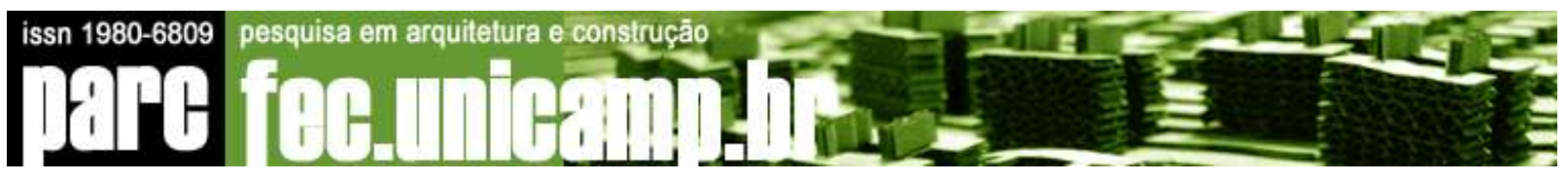

Mestres e oficiais transitavam de região em região levando consigo o conhecimento que haviam adquirido, era na sua essência de ordem empírica e tradicional, obtido através de uma lenta formação e era transmitido de feição corporativa (Pereira in Teixeira, 2004: 33).

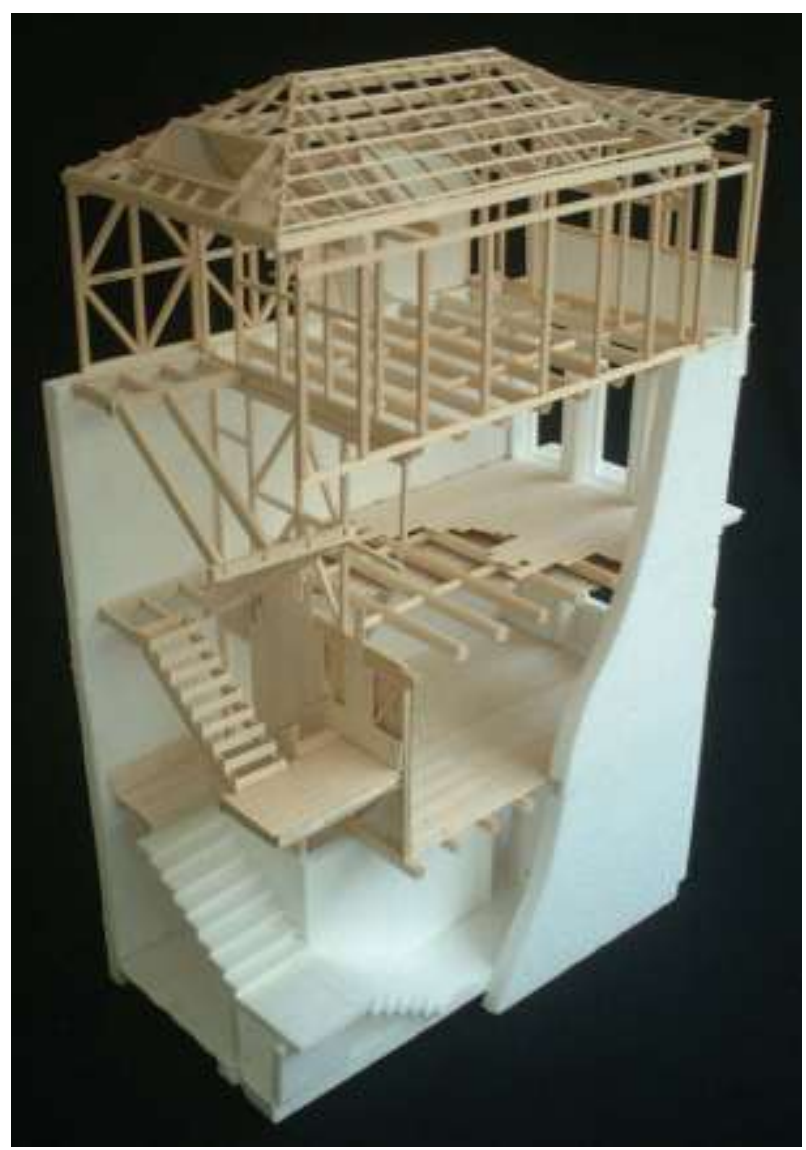

FIGURA 7: Maqueta de uma casa localizada na rua do Dr. Barbosa de Castro. Pormenor da estrutura da caixa de escadas, com os dois primeiros lanços de pedra, e da estrutura do último piso, integralmente de madeira. Neste exemplo, a claraboia, de forma retangular, está localizada na tacaniça da fachada posterior, encostada à Muralha Fernandina. Maqueta elaborada por um grupo de alunos do ano letivo 2001/2002 - FAUP (Teixeira, 2004: 91).

Relativamente ao século XVIII, Joaquim Teixeira (2004, 37), lembra que a revolução industrial que teve origem na Inglaterra neste período e que se afirmou durante o século seguinte, não irá alterar em muito os métodos de construção e os sistemas construtivos até à primeira metade do século XIX, continuando-se a utilizar os materiais tradicionais.

Os novos contributos para o processo construtivo, foram essencialmente determinado, pela experiência empírica decorrente do uso constante de certos materiais ou da repetição de soluções construtivas. 


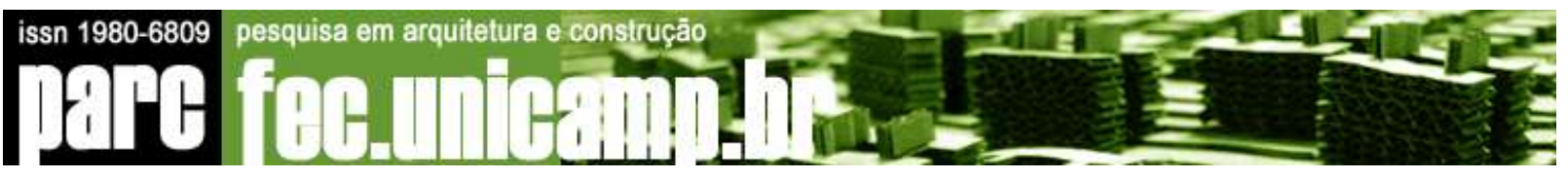

Depois da segunda metade do século XVIII, com a expansão da cidade do Porto e à imagem do que sucedeu aquando da reconstrução de Lisboa, o desenho e a intervenção urbana foram metodizados o que serviu para o aperfeiçoamento dos sistemas construtivos usados nas habitações correntes.

No início do século XIX os problemas construtivos são abordados de duas formas distintas:

"A primeira, mais intuitiva e inicialmente mais eficaz, trata de encontrar na tradição, através da pura adaptação dos sistemas e transposição de formas, os métodos para fazer avançar o processo construtivo. A segunda, pretende incorporar, talvez com excessiva urgência, o pouco que ainda se manipula do conhecimento científico." (Teixeira, 2004: 38).

No século XIX, a revolução industrial iniciada no período anterior encontrará maior expressão. Surge a especialização das atividades artesanais e industriais, a mecanização e a pré-fabricação.

O estudo de Joaquim Teixeira que tem vindo a ser referido, apresenta uma descrição pormenorizada do sistema construtivo deste tipo de casa, entre os séculos XVII e XIX, descreve os materiais utilizados, as unidades de medida e de peso, as estruturas primárias, as estruturas secundárias, as caixilharias exteriores, as caixilharias interiores e elementos singulares como os algerozes, mísulas, cornijas, chaminés, platibandas, óculos, frestas e postigos, entre outros também referidos.

Francisco Barata Fernandes (1996: 14) considera que a casa burguesa do Porto mantém características estruturantes durante um longo período histórico, que vai desde os finais do século XVI, princípios do século XVII até à primeira metade do século XIX. Sendo parte destas características os materiais de construção e os elementos de identidade arquitetónica.

Joaquim Teixeira (2004: 45) possivelmente inspirado por este trabalho descreve um modelo de casa abstrato que reúne características comuns aos séculos XVII, XVIII e XIX, conseguindo uma síntese dos aspetos que caracterizam o sistema construtivo aqui tratado.

Esta abordagem de Joaquim Teixeira, complementada com outras publicações, serve como ponto de partida para um melhor conhecimento de como a casa burguesa do Porto era construída, em particular o momento compreendido entre a segunda metade do século XVIII e a primeira do século XIX que será tratado neste doutoramento. 


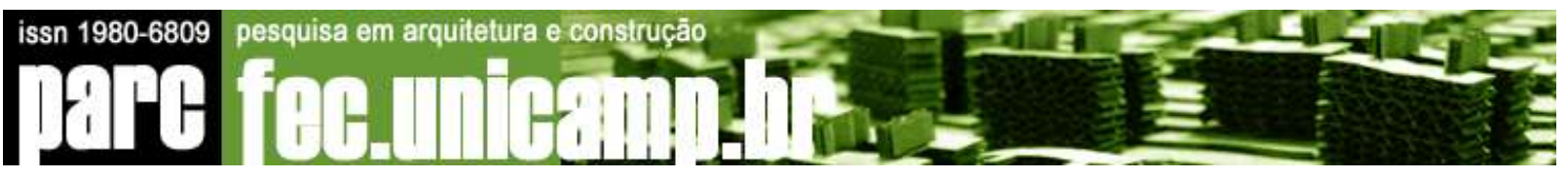

\section{O sistema BIM}

O papel da tecnologia de informação e comunicação e em particular do sistema BIM assume algum relevo quando a intensão é pensar o processo de projeto na reabilitação da casa burguesa do Porto. A articulação deste sistema com a teoria das gramáticas da forma no ato de projetar, pode condicionar de forma positiva o seu desenvolvimento. A sistematização da informação necessária associada a soluções construtivas e de desenho, pode ser sinónimo de decisões mais sustentáveis economicamente.

Em projetos BIM a estruturação adequada de informação desde as suas fases iniciais tem sido crucial para o seu correto desenvolvimento (Penttilä, 2007: 296).

Apesar das ferramentas ou tecnologias aplicadas, o alargado espetro de necessidades impostas pela sociedade atual tem contribuído para uma reformulação do perfil do arquiteto (Penttilä 2007: 296).

Building Information Modeling (Modelação de Informação da Construção) trata-se de um sistema ou de um conjunto de sistemas que permitem aos utilizadores integrarem e reutilizarem informação relativa à construção ao longo do ciclo de vida de um determinado edifício (Eastman et al., 2006: 758).

A necessidade de coordenar de forma interativa os diferentes contributos das várias disciplinas que compõem o projeto, ao longo do ciclo de vida dos edifícios, tem sido uma característica na categorização de projetos BIM (Penttilä , 2007: 301).

R. Howard e B. Björk (2008) são de opinião que a representação de toda a informação necessária para descrever os edifícios ao longo do projeto, há muito que é um objetivo. O uso de computadores, na replicação de formas tradicionais de representar informações destinadas à edificação tem sido mais fácil de conseguir através de diferentes aplicações. Hoje em dia já podemos considerar essa possibilidade, mas a necessidade de integrar todas as partes envolvidas no processo e a forma como a diferente informação é organizada, tem sido a limitação fundamental no uso do sistema BIM.

Segundo estes autores, o conceito já data do final dos anos 70 do século passado, mas sofre um grande impulso por volta de 1985 com a norma ISO STEP, STEP significa Standard for the Exange of Product Data (Eastman, 1999: 130). Em meados dos anos 90 a International Alliance for Ineroperability (IAI) apropria-se da normalização de modelos de informação e em 1997 surge a primeira versão da IFC (Industry Foundation Classes), especificação baseada na interoperabilidade da construção. Embora existam algumas 


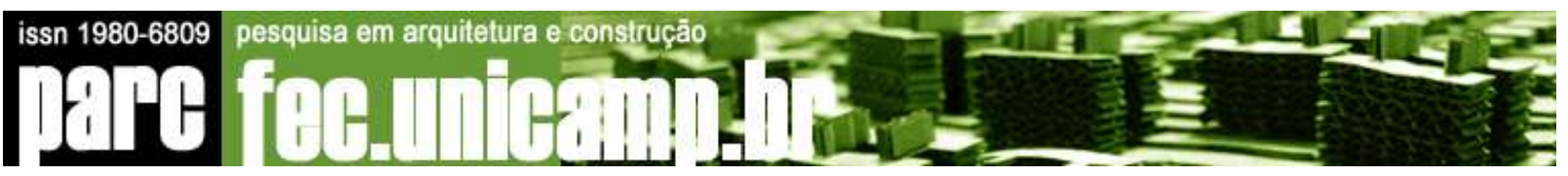

aplicações informáticas baseadas nesta especificação, o conceito não é amplamente utilizado na prática.

A normalização da informação no processo construtivo deve ser mais efetiva, facilitando assim a sua aplicação e distribuição. A cooperação entre arquitetos, empresas de construção, consultores e autoridades através de uma troca de informação eficaz é um fator de sucesso (Diaz,2007: 534).

As ferramentas de projeto BIM permitem extrair diferentes vistas de um modelo de edifício para a produção de desenhos ou outros usos. Estas diferentes vistas são automaticamente consistentes, pois cada objeto é só definido uma vez, como na realidade. Esta consistência de desenho ao contrário dos processos anteriores elimina muitos erros. As ferramentas BIM modernas vão mais além, estas definem os objetos parametricamente. Os objetos são definidos como parâmetros e em relação a outros objetos, assim se um determinado objeto muda, o que lhe está relacionado também. Os objetos paramétricos reconstroem-se automaticamente de acordo com as regras que contêm. Estas regras podem ser simples ou complexas com um grande nível de detalhe chegando à caracterização, por exemplo, de uma ligação física (Eastman (2009).

Eastman (2006: 758) afirma que o conhecimento de sistemas paramétricos de modelação tridimensional são centrais para o BIM e para o ciclo de vida dos edifícios, apontando as seguintes razões:

- O edifício é composto por componentes geométricos e a informação geométrica é fundamental para o BIM;

- A modelação paramétrica fornece os mecanismos necessários para traduzir e introduzir conhecimento especializado como expressões geométricas explícitas, que podem gerar a informação do edifício, especialmente informação geométrica que pode facilitar a geração de modelações detalhadas.

- A manutenção da validade da informação gerada é crucial. A integridade semântica do modelo de um determinado edifício pode ser mantida, tendo como base as limitações geométricas impostas e regras específicas.

Temos como exemplo de sistemas paramétricos de modelação tridimensional na área da arquitetura, engenharia e construção, o ArchiCAD, o Bentley Architecture and Structure, o Revit Building e Revit Structures. 


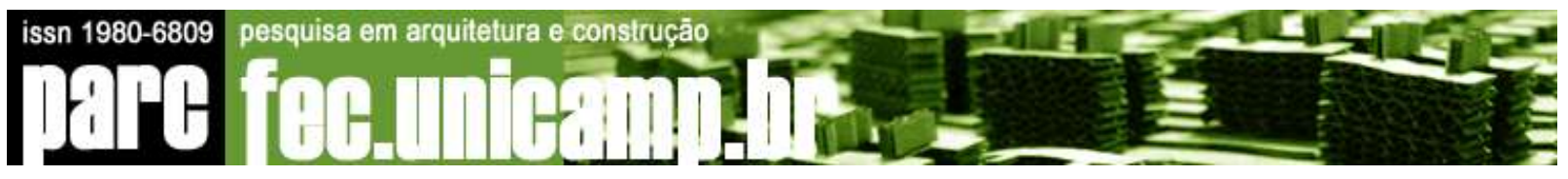

Anders Hermund (2009: 75) defende que uma aplicação adequada do sistema BIM no projeto de arquitetura pode significar ganhos económicos. No entanto, reflete as suas consequências nas diferentes fases de projeto e na qualidade da arquitetura.

Os primeiros passos em projeto são sempre vagos e pouco estruturados, neste estágio a informação deve ser o mais versátil e flexível. O sistema BIM é sobretudo um método a ser aplicado em fases adiantadas de projeto. Este sistema continua a ser recomendado em fases iniciais mas requer ainda alguma investigação (Penttilä 2007: 301). É importante referir que para que possa ser usado pelo arquiteto deve ser pensada a sua aplicação já em fases preliminares de projeto.

Um sistema baseado em referências, que aponte para diferentes sistemas onde a informação é armazenada sem necessariamente incluí-la num modelo geométrico, pode ser a melhor maneira de garantir espaço para a criatividade necessária ao projeto (Hermund 2009: 81).

Num involucro rígido de granito, o interior da casa burguesa do Porto desenvolve-se de forma flexível e adaptável, através de diferentes estruturas de madeira. Os seus acrescentos, adaptações sofridas ao longo da vida dos edifícios, serviam-se deste material em construções ligeiras que exploravam as suas potencialidades.

Um conhecimento transmitido de forma cooperativa foi aperfeiçoando o sistema construtivo da casa burguesa do Porto, transversal a um longo período de tempo.

Um conhecimento abrangente relativo à construção será fundamental na descrição das soluções construtivas que se pretende desenvolver. O modo de tratar os dados recolhidos, na amostra relativa à fase lluminista da casa burguesa do Porto, assim como estudar formas inovadoras de os representar e atualizar pode ter como possibilidade os sistemas de Modelação de Informação da Construção.

\section{Conclusão}

A integração do centro antigo, como parte de uma configuração mais alargada é potenciada pela preservação do conhecimento e valor simbólico patente no seu património histórico. Tema sensível que apesar de não ser objeto de estudo, revela-se como uma possibilidade.

O propósito da investigação em desenvolvimento é apoiar a reabilitação da casa burguesa do Porto, pelo seu protagonismo na cidade. 


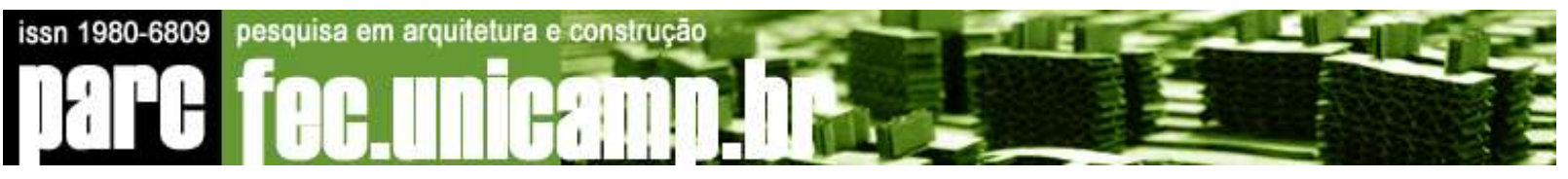

Podemos encontrar exemplos do momento a ser estudado, a fase lluminista (Barata Fernandes 1996), dentro das antigas muralhas, assim como nos eixos de expansão Almadina. Para além do centro histórico está a ser considerada a sua envolvente imediata também de intervenção prioritária.

O conhecimento tipológico pode ser um componente fundamental no processo de projeto, sobretudo no campo da reabilitação arquitetónica. O tipo arquitetónico deve ser considerado como um sistema de transformações e não uma simples categoria de análise.

O objetivo será desenvolver uma gramática da forma composta que sistematize o conhecimento recolhido. Definição de soluções tipo de desenho e soluções tipo construtivas que na sua descrição possam ser úteis ao processo de projeto, simplificando e tornando mais económica a reabilitação da casa burguesa do Porto. Terá como parâmetros fundamentais a topologia e geometria, materiais de construção e sistemas construtivos (fig. 8, 9). Tendo como base o suporte da decisão em projeto, esta componente descritiva poderá servir no futuro, de base para uma implementação informática útil à prática do arquiteto.

$\mathrm{Na}$ elaboração de uma gramática da forma que codifique uma linguagem específica de composição podem ser combinadas formas, rótulos e pesos (Stiny, 1981; 1992). Estas gramáticas podem combinar vários destes componentes na codificação de diferentes modos de ver e descrever composições, constituindo assim uma gramática da forma composta (Duarte, 2005).

A componente construtiva contribuirá com parâmetros fundamentais a esta gramática. Compreender aspetos essenciais da construção, pode conferir uma dimensão mais sensível ao sistema construtivo original e aqueles que surgiram como alternativa. $O$ modo de codificar os dados recolhidos na gramática pretendida, assim como estudar formas inovadoras de os representar e atualizar pode ter como possibilidade os sistemas de Modelação de Informação da Construção.

A aplicação desta gramática a outros casos de estudo sai reforçada com a influência que este tipo de edifícios terá sofrido de cidades italianas como Génova, Bolonha, Pavia, Florença ou mesmo de cidades do Norte da Europa (Barata Fernandes, 1996: 68).

Neste artigo, desde o caso de estudo, enquadramento histórico, componente formal, componente construtiva até à metodologia que relacionará todos os componentes, foram enunciadas as referências fundamentais para a investigação que se está a desenvolver. 

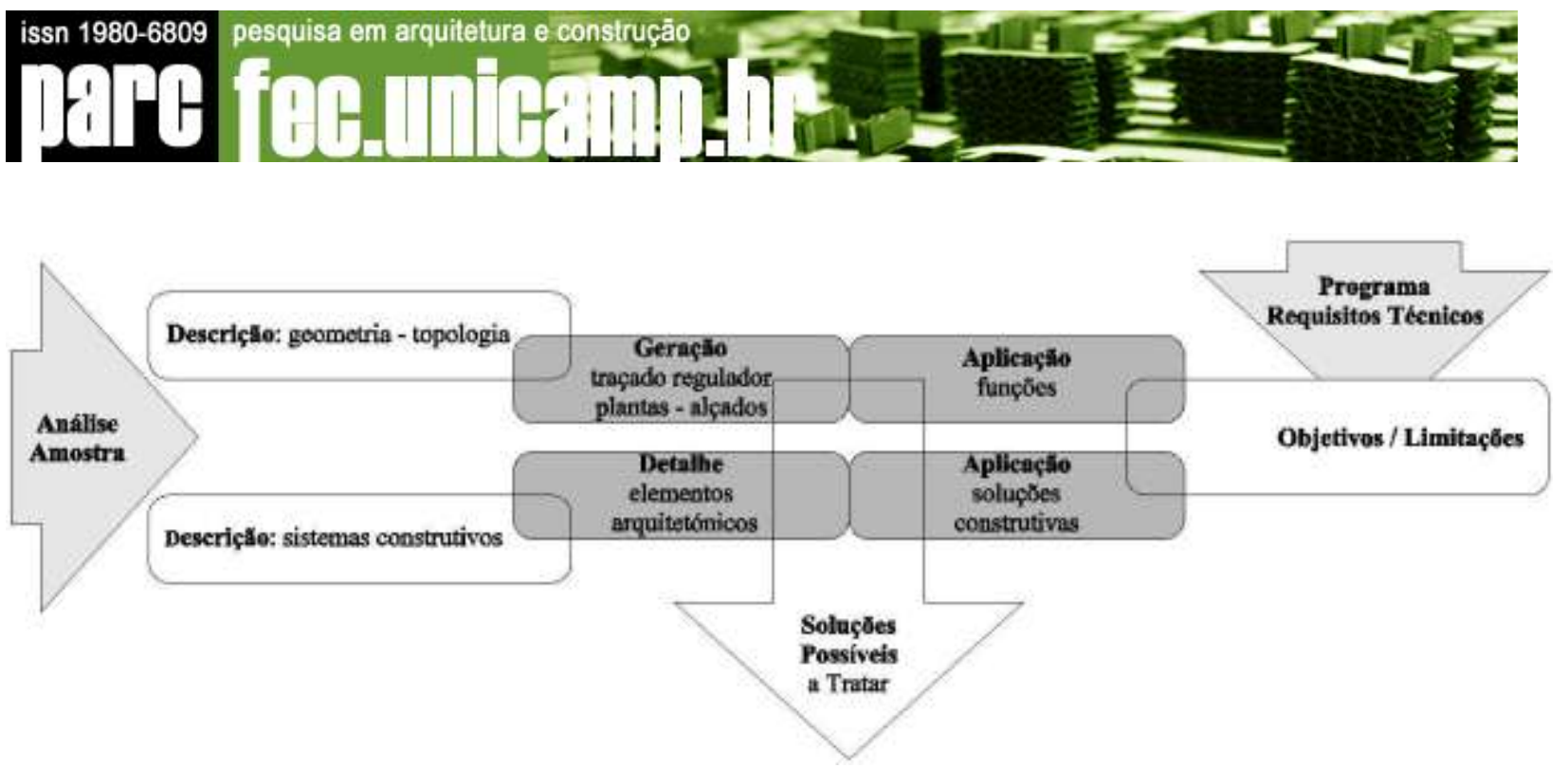

FIGURA 8: Esquema representativo do funcionamento da gramática da forma a elaborar. Adaptado de Parish \& Müller (2001).

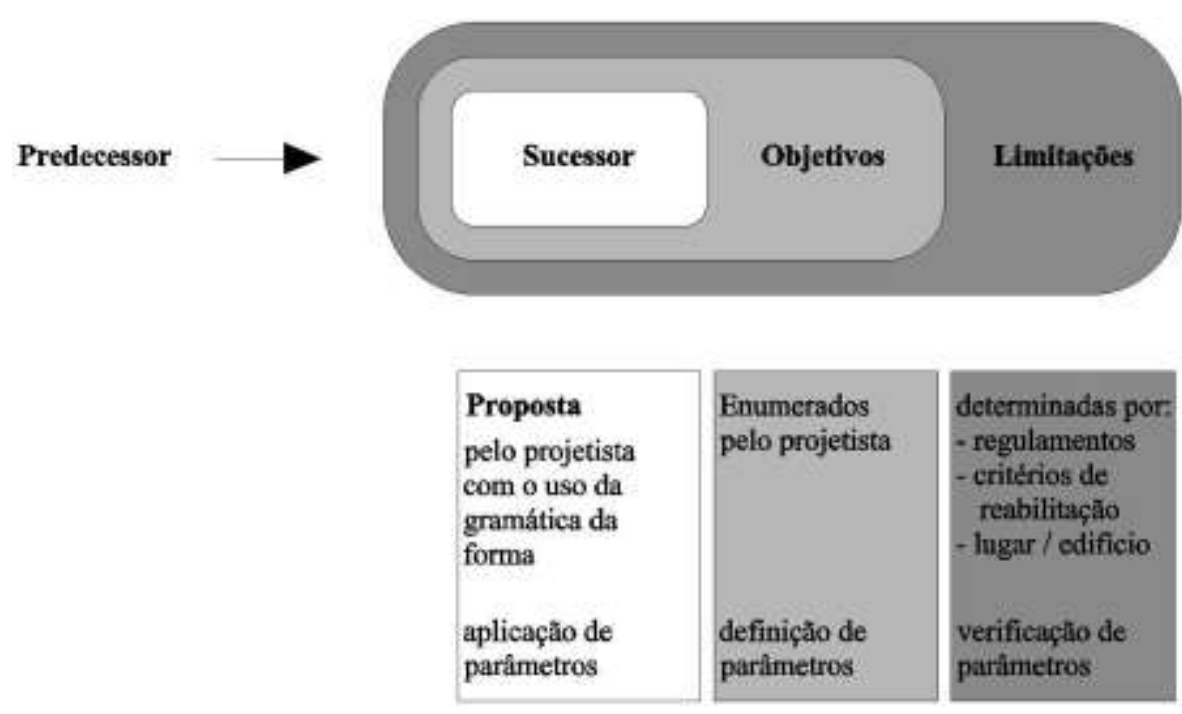

FIGURA 9: Esquema representativo do processo para a elaboração da proposta. Adaptado de Parish \& Müller (2001).

\section{Referências}

Ascher, F. Novos Princípios do Urbanismo. Lisboa: Livros Horizonte, 2008.

Barata Fernandes, F. Transformação e Permanência na Habitação Portuense - As

formas da casa na forma da cidade. Porto: Edições FAUP, 1996.

Choay, F. Alegoria do Património. Coimbra: Edições 70, 2008. 
Diaz, J. Holistic Cost-Information Management in Building and Construction. Predicting the Future. 25th eCAADe Conference Proceedings. Frankfurt am Main, p. 533-539. 2007.

Duarte, J. P. Towards the mass customization of housing: the grammar of Siza's houses at Malagueira. Environement and Planning B: Planning and Design, v. 32, p. 347-380. 2005.

Duarte, J. P. A discursive grammar for customizing mass housing: the case of Siza's houses at Malagueira. Elsevier: Automation in Construction, v. 14(2), p. 265-275. 2004.

Eastman, C. What is BIM? Digital Building Lab, 2009. Disponível em http://bim.arch.gatech. edu/?id=402 [Acedido a 11 de Julho 2011].

Eastman, C. M.; Lee, G.; Sacks, R. Specifying parametric building object behavior (BOB) for a building information modeling system. Elsevier: Automation in Construction, v.15, p. 758-776. 2006.

Eastman, C. Building Product Models: Computer Environments Supporting Design and Construction. Boca Raton FL: CRC Press. 1999.

Franpton, K. Introdução ao Estudo da Cultura Tectónica. Matosinhos: Associação dos Arquitetos Portugueses, 1998.

Frier, M.; Fisker A. M.; Kirkegaard P. H. Tectonic theory and practice: interiority in the future prefab home. Guimarães: ICSA. 2010.

Hermund, A. Building Information Modeling in the Architectural Design Phases - And Why Compulsory BIM Can Provoke Distress Among Architects. The New Realm of Architectural Design. 27th eCAADe Conference Proceedings. Istanbul, p. 75-82. 2009.

Howard, R.; Björk, B. Building information modelling - Experts' views on standardisation and industry deployment, Advanced Engineering Informatics, v. 22.2008.

Knight, T. W. Shape Grammars in Education and Practice: History and Prospects.1998. Disponível em http://www.mit.edu/ tknight/IJDC/ [Acedido a 8 de Maio 2011].

Mota, N. A Arquitetura do Quotidiano: Público e Privado no Espaço Doméstico da Burguesia Portuense no Final do Século XIX. Coimbra: e|d|arq, 2010.

Oliveira, V. E.; Galhano, F. Arquitetura Tradicional Portuguesa. Lisboa: Publicações D. Quixote, 1992.

Parish, Y. I. H.; Müller, P. Procedural Modeling of Cities. ACM SIGGRAPH, p.12-17.2001 


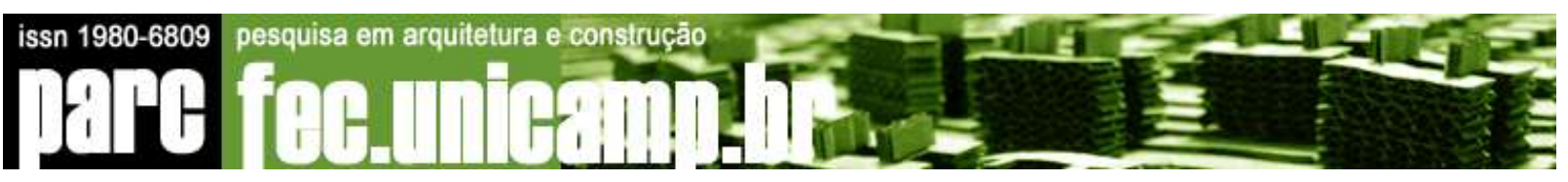

Pentitilä, H. Early Architectural Design and BIM. Computer Aided Architectural Design Futures. Proceedings of the 12th International Conference on Computer Aided Architectural Design Futures. Sydney, p. 291-302. 2007.

Rasmussen, S. T. Découvrir I' Architecture. Paris: Le Linteau, 2002.

Semper, G. Style in the Technical and Tectonic Arts; or, Practical Aesthetics. LA: Getty Publ, 2004.

Semper, G. The Four Elements of Architecture and other writings. NY: Cambridge Univ. Press, 1989.

Stiny, G. Weights. Environement and Planning B: Planning and Design, v.19, p. 413430.1992.

Stiny, G. A note on the description of designs. Environment and Planning B: Planning and Design, v.8, p. 257-267.1981.

Stiny, G.; Gips, J. Shape Grammars and the Generative Specification of Painting and Sculpture. In C. V. Freiman, Information Processing 71, Amsterdam: p.1460-1465. North-Holland. Republished in Petrocelli O. R. 1972. The Best Computer Papers of 1971: p.125-135. Auerbach: Philadelphia, 1972.

Teixeira, J. J. L. Descrição do sistema construtivo da casa burguesa do Porto entre os séculos XVII e XIX. Contributo para uma história da construção arquitetónica em Portugal. Provas de aptidão pedagógica e capacidade científica. Porto: FAUP, 2004.

Vieira de Almeida, P. Apontamentos para uma Teoria da Arquitetura. Lisboa: Livros Horizonte, 2008. 